\title{
Pleuroperitoneal shunt for recurrent malignant pleural effusions
}

\author{
Victor Tsang, H C Fernando, Peter Goldstraw
}

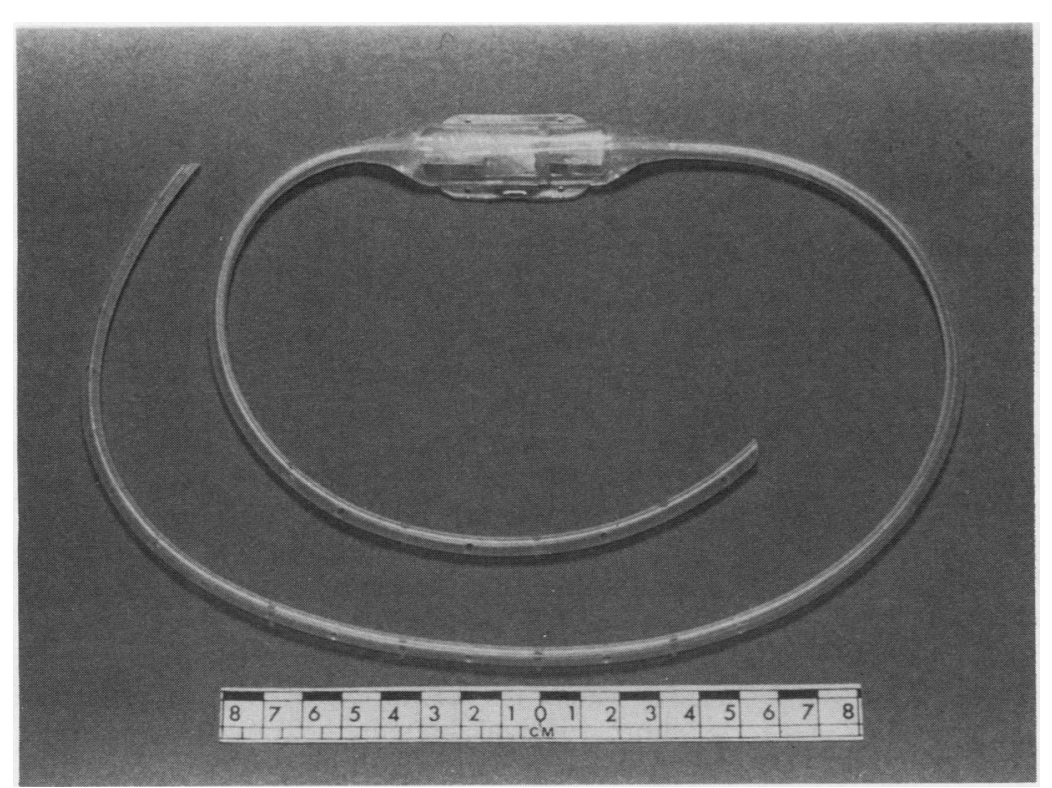

Figure 1 Denver pleuroperitoneal shunt.

\begin{abstract}
Department of Cardiothoracic Surgery, Brompton Hospital, London V Tsang

H C Fernando

P Goldstraw

Address for reprint requests: Mr Peter Goldstraw, Brompton Hospital, London SW3 6HP.

Accepted 8 February 1990

Abstract

The therapeutic options available for the management of malignant pleural effusions associated with a restricting malignant cortex remain unsatisfactory. The efficacy of pleuroperitoneal shunts was evaluated in 16 patients with recurrent malignant effusions. There were no operative deaths; one patient died on the third postoperative day as a result of lymphangitis carcinomatosa. The median hospital stay was five (range 321) days. Palliation was obtained in all but one of the other 15 patients. There was no appreciable reaccumulation of pleural fluid as judged by radiography. Two patients developed occlusion of the shunt. In one case this was due to blood clots in the pleural catheter and necessitated insertion of a new shunt. The other shunt was removed because of obstructing infected fibrin debris, and a rib resection was performed. There were eight deaths related to the underlying malignancy after a mean interval of 7.3 (range 1.5-23) months. The other six patients are still alive, with a mean survival of 11.0 (range 5-20) months, and have achieved good symptomatic relief. The insertion of a pleuroperitoneal shunt can offer effective palliation for patients with recurrent malignant pleural effusions.
\end{abstract}

Malignant pleural effusion is a potentially serious problem in patients who already have a relatively short life expectancy. In most patients palliation can be achieved with thoracocentesis or sclerotherapy, or both. Ineffective treatment of the pleural effusion, however, may result in multiple hospital admissions for painful repeated pleural fluid aspirations and intercostal tube drainage. Subsequent formation of adhesions predisposes to fluid loculation, and possible empyema. The presence of a malignant restrictive cortex may interfere with the apposition of the visceral and parietal pleural surfaces. Palliative choices are limited in these difficult circumstances. Decortication, combined with sclerotherapy or pleurectomy, is a major procedure with a high morbidity and mortality, and is best avoided in patients with a limited life expectancy.

This report describes our experience of using pleuroperitoneal shunts (Denver Biomaterials) in managing recurrent malignant pleural effusions.

\section{Methods}

From October 1986 to June 198916 patients (age range 42-79 years with a mean age of 61) underwent insertion of a pleuroperitoneal shunt (fig 1) for recurrent malignant pleural effusions. Their underlying malignancy (table) was mesothelioma in eight cases, carcinoma of the lung in three, and carcinoma of the breast in five. The malignant pleural effusion was considered unresponsive to medical treatment in all cases. All the patients had required multiple hospital admissions for a combination of repeated thoracocentesis $(43$ attempts), intercostal tube drainage (seven attempts), and sclerotherapy (nine attempts with talc, tetracycline, or mustine). The 16 patients constituted only $20 \%$ of our total patients with malignant pleural effusion during this period. Talc pleurodesis is still our treatment of choice if possible. The indication for the insertion of a pleuroperitoneal shunt was based on the operative findings, as preoperative clinical assessment and chest radiography were unreliable in identifying the patients suitable for shunting. Despite the uncertainty of this approach, it was readily accepted by the patients after careful explanation.

General anaesthesia was used in all our cases, with prophylactic intravenous gentamicin and flucloxacillin. The patient was 


\begin{tabular}{|c|c|c|c|c|c|c|}
\hline $\begin{array}{l}\text { Case } \\
\text { No }\end{array}$ & $\begin{array}{l}\text { Age }(y), \\
\operatorname{sex}\end{array}$ & Diagnosis & $\begin{array}{l}\text { Pre-shunt } \\
\text { treatment }\end{array}$ & $\begin{array}{l}\text { Hospital } \\
\text { stay } \\
\text { (days) }\end{array}$ & $\begin{array}{l}\text { Shunt } \\
\text { function }\end{array}$ & $\begin{array}{l}\text { Survival } \\
\text { (months) } \dagger\end{array}$ \\
\hline 1 & $42, F$ & Mesothelioma & $\begin{array}{l}\mathrm{T}(1) \\
\mathrm{CT}(1)\end{array}$ & 5 & Good & 5 \\
\hline 2 & $64, M$ & Lung carcinoma & $\begin{array}{l}T(2) \\
S(1)\end{array}$ & 5 & Good & 2 \\
\hline 3 & $66, \mathrm{~F}$ & Mesothelioma & $\begin{array}{l}T(5) \\
C T(1)\end{array}$ & 7 & Good & 7 \\
\hline 4 & $79, M$ & Mesothelioma & $\begin{array}{l}\mathrm{T}(2) \\
\mathrm{CT}(1)\end{array}$ & 7 & $\begin{array}{l}\text { Blocked (blood clot; } \\
\text { new shunt) }\end{array}$ & 1.5 \\
\hline 5 & $67, M$ & Mesothelioma & $\begin{array}{l}T(4) \\
S(1)\end{array}$ & 4 & Good & 23 \\
\hline 6 & $59, \mathrm{~F}$ & Breast carcinoma & $\begin{array}{l}T(2) \\
S(1)\end{array}$ & 11 & Good & 11 \\
\hline 7 & $61, M$ & Mesothelioma & $\begin{array}{l}\mathrm{T}(1) \\
\mathrm{CT}(1)\end{array}$ & 4 & Good & 7 \\
\hline 8 & $51, \mathrm{~F}$ & Breast carcinoma & $T(4)$ & 4 & Good & 20: alive \\
\hline 9 & $68, M$ & Lung carcinoma & $\mathrm{T}(4)$ & 5 & $\begin{array}{l}\text { Good (tumour at } \\
\text { thoracotomy site) }\end{array}$ & 3 \\
\hline $\begin{array}{l}10 \\
11\end{array}$ & $\begin{array}{l}57, M \\
56, \mathrm{~F}\end{array}$ & $\begin{array}{l}\text { Mesothelioma } \\
\text { Breast carcinoma }\end{array}$ & $\begin{array}{l}T(2) \\
T \text { (5) } \\
S(3)\end{array}$ & $\begin{array}{r}21 \\
4\end{array}$ & $\begin{array}{l}\text { Good } \\
\text { Good }\end{array}$ & $\begin{array}{l}\text { 9: alive } \\
\text { 10: alive }\end{array}$ \\
\hline 12 & $72, M$ & Mesothelioma & $\mathrm{T}(3)$ & 11 & $\begin{array}{l}\text { Blocked (infected fibrin } \\
\text { debris; shunt removed) }\end{array}$ & 11: alive \\
\hline 13 & $59, M$ & Mesothelioma & $\begin{array}{l}T(2) \\
\text { CT }(1)\end{array}$ & 5 & Good & 10: alive \\
\hline 14 & $71, M$ & Lung carcinoma & $\begin{array}{l}\mathrm{T}(2) \\
\mathrm{CT}(1) \\
\mathrm{S}(1)\end{array}$ & 5 & Good & 5: alive \\
\hline $\begin{array}{l}15 \\
16\end{array}$ & $\begin{array}{l}46, F \\
65, F\end{array}$ & $\begin{array}{l}\text { Breast carcinoma } \\
\text { Breast carcinoma } \\
\text { Lymphangitis } \\
\text { carcinomatosa }\end{array}$ & $\begin{array}{l}T(3) \\
T(1) \\
S(1)\end{array}$ & $\begin{array}{l}3 \\
3\end{array}$ & Good & $\begin{array}{l}\text { 8: alive } \\
3 \text { days }\end{array}$ \\
\hline
\end{tabular}

^Number of attempts in parentheses. †Updated to March 1990.

$\mathrm{T}$-thoracocentesis; CT -chest tube; $\mathrm{S}-$ sclerotherapy: tetracycline, talc, or mustine.

placed in a supine position with the affected side of the chest slightly raised. The initial approach was by either thoracoscopy or a short thoracotomy, depending on the radiological findings of fluid loculation and possible adhesions. The thoracotomy was a $7 \mathrm{~cm}$ submammary incision. The pleural effusion was drained completely, and adhesions were divided by electrocautery, a thorough assessment of the pleural and lung parenchymal lesions thus being permitted. In the presence of a thickened restrictive cortex encasing the lung, most commonly the lower lobe, which did not expand with a high pressure ventilation, chemical pleurodesis was considered inappropriate, and a pleuroperitoneal shunt was inserted. The surgical technique of shunt insertion has been described. ${ }^{1}$ A $2-3 \mathrm{~cm}$ transverse incision was made in the appropriate hypochondrium, and the peritoneal cavity was exposed. The pleuroperitoneal shunt was tunnelled from the chest to the abdomen, with the shunt pumping chamber lodged in a subcutaneous pocket overlying the costal margin. Postoperatively, the pump chamber was compressed regularly for the first 24 hours, minimising the risk of early shunt occlusion. Later the patients or members of their family were taught to compress the pump chamber several times a day. The patients were followed up for recurrences of respiratory symptoms and pleural effusion on the chest radiographs. Doppler ultrasound to assess shunt function was also attempted.

\section{Results}

Details of the patients, the functioning of the shunts, and survival are summarised in the table. There were no deaths during operation.
One death occurred on the third postoperative day (case 16) from lymphangitis carcinomatosa. Among the remaining 15 patients the median hospital stay was five (range 3-21) days.

Two patients developed shunt occlusion. One occlusion (case 4), two weeks after surgery, due to blood clots in the pleural catheter, was related to multiple pleural biopsies at the time the shunt was inserted. A new shunt was put in, which remained functioning until the patient died of his underlying malignancy one month later. The second patient (case 12) had a recurrence of the pleural effusion three months after his shunt was inserted, and when the site was explored again infected fibrin debris was found to be obstructing the valve mechanism of the shunt. The shunt was removed, and a short rib resection was created at the base of the cavity. The patient was later discharged home with open tube drainage.

One patient (case 9) was found to have tumour growing at the thoracotomy wound four weeks after insertion of the shunt. This was treated with radiotherapy. He died two months later with no recurrence of the pleural effusion.

In all but one of the 15 patients good palliation was achieved with no recurrence of symptoms and no appreciable reaccumulation of pleural fluid evident on the chest radiographs. The mean duration of shunt functioning was 8.6 months, ranging from 1 to 23 months. Eight deaths were related to the underlying malignancy after a mean interval of $7 \cdot 3$ (range $1 \cdot 5-23$ ) months. Even those with a short survival benefited from the palliative effect of the pleuroperitoneal shunt. The other six patients are still alive, with a mean survival of 11.0 (range 5-20) months, having achieved 
good symptomatic relief. In the patient who survived the longest (No 5, 23 months), however, there was clinical and cytological evidence that peritoneal metastases were caused by malignant mesothelioma cells carried by the shunt. He required abdominal paracentesis for ascites (he died a month later).

\section{Discussion}

The life expectancy of patients with malignant pleural effusions is short. ${ }^{2}$ The malignant effusions often persist, and few options are available to prevent fluid reaccumulation and provide prolonged palliation. ${ }^{23}$ The principles underlying effective local treatment for malignant pleural effusion are to drain the pleural fluid completely, then instill an effective sclerosing agent and ensure that the lung is completely re-expanded during the process of pleurodesis. ${ }^{3}$ Talc has been shown to be the most effective sclerosing agent, with a reported success rate of $93 \%$; and tetracycline, another agent commonly used, has a success rate of around $71 \%{ }^{3}$ Pleurodesis cannot succeed, however, if the lung is restricted by a malignant cortex preventing apposition of the visceral and parietal surfaces. Repeated thoracocentesis and attempts at pleurodesis are debilitating and may result in fluid loculation and empyema. In these difficult circumstances the means of possible palliation are limited. Pleurectomy and decortication for lung encasement may not be beneficial, and have a considerable morbidity and mortality. ${ }^{4}$

The use of a modified peritoneoatrial Holter valve $^{5}$ as a pleuroperitoneal shunt to produce effective palliation was first reported by Wesse and Schouten in $1982 .{ }^{6}$ Since then a modified peritoneovenous shunt has been used with success in controlling intractable benign and malignant pleural effusions ${ }^{1}$ and chylothorax. ${ }^{7}$
The Denver pleuroperitoneal shunt, used in all our 16 patients, is currently available commercially. The two unidirectional valves of the shunt are designed to open at a positive pressure of about $1 \mathrm{~cm} \mathrm{H}_{2} \mathrm{O}$. As the intrapleural pressure in a normal man reaches $4 \mathrm{~cm} \mathrm{H}_{2} \mathrm{O}$ or more at expiration, ${ }^{8}$ theoretically spontaneous flow of fluid from the pleural cavity into the peritoneal cavity should occur with each breath. In the presence of a pleural effusion the greater differential pressure between the pleural space and the intra-abdominal cavity will allow a larger amount of fluid to flow. At a low pressure gradient the passage of the pleural fluid can be induced by compressing the pump chamber percutaneously, which also helps to maintain the patency of the shunt.

General anaesthesia was used in all our cases without any perioperative complication, though the procedure could be done under local anaesthesia. The decision to insert a pleuroperitoneal shunt, however, was made only after the pleural and lung parenchymal lesions had been assessed. Any loculations or adhesions should be broken down. A restrictive cortex prevents re-expansion of the underlying lung, despite high pressure ventilation, and chemical pleurodesis does not achieve a satisfactory outcome. A more effective approach is provided by the continuous shunting of pleural fluid into the peritoneal cavity. In time the pleural space may be obliterated by the progression of the local malignant disease, combined perhaps with the expansion of islands of normal lung tissue around the restrictive cortex. Whether the shunt would then make any difference in the reaccumulation of the effusion is a matter of debate. Our assessment of shunt function was essentially clinical, being based on the recurrences of symptoms and the appearance of pleural fluid on the chest radiographs (fig 2). Even these could cause difficulty at times, because shortness of breath and increas-
Figure 2 Chest radiographs before and six months after insertion of $a$ pleuroperitoneal shunt (arrow) for recurrent malignant left pleural effusions.

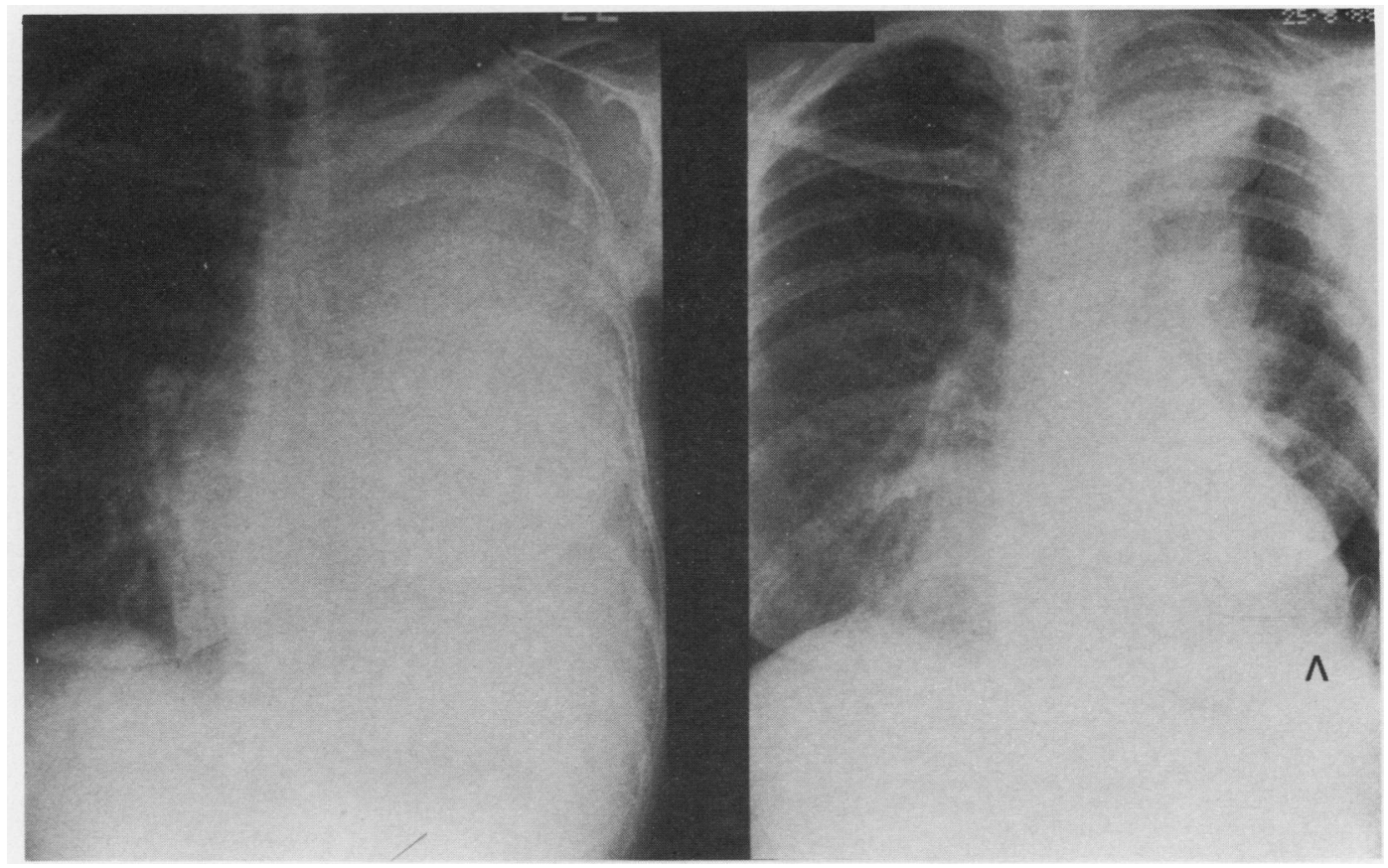


ing pulmonary shadows on the chest radiographs might represent the progression of local disease rather than recurrence of the effusion. Despite the fact that our assessment of shunt function may seem to be unscientific, we considered it inappropriate to perform any unnecessary investigative procedures in these patients. Doppler ultrasound was used to assess the functioning of the shunts, but this proved unreliable in terms of detecting flow.

No shunt complications were reported in other series. ${ }^{1}$ The two shunt occlusions in our series, one due to blood clot and the other to infected fibrin debris, reveal potential risks. Haemostasis is particularly important in cases in which concomitant multiple vascular pleural tumour biopsies are carried out. Infected pleural fluid related to previous repeated thoracocentesis should be considered normally as a contraindication to the insertion of a shunt.

Peritoneal dissemination from shunting of tumour cells is a potential risk. Our longest survivor, who lived for 23 months after insertion of the pleuroperitoneal shunt, developed malignant ascites. Thus effective palliation in a short life span has to be balanced against the risk of tumour implantation within the peritoneal cavity in the long term. A pathological review of pleurovenous shunts in patients with malignant ascites suggested no increased incidence of clinically important disseminated malignancy in the short term. ${ }^{9}$

Insertion of the pleuroperitoneal shunts in our series proved to be a useful procedure, requiring a relatively short hospital stay. No patient with good shunt function needed further admissions to hospital for repeated painful drainage of pleural fluid, which was essentially our aim, so that the patients could have a better quality of life. After failure to achieve satisfactory palliation for malignant pleural effusions early referral for insertion of a shunt may benefit these patients, as repeated thoracocentesis and intercostal tube drainage are often traumatic and detrimental.

In conclusion, chemical pleurodesis remains the treatment of choice for malignant pleural effusions. For recurrent cases in which malignancy around the lung cortex restricts expansion of the underlying lung a pleuroperitoneal shunt may be an effective method of palliation.

1 Cimochowski GE, Joyner LR, Fardin R, Sarama R, Maran A. Pleuroperitoneal shunting for recalcitrant pleura effusions. J Thorac Cardiovasc Surg 1986;92:866-70.

2 Anderson CB, Philpott GW, Ferguson TB. The treatment of malignant pleural effusions. Cancer 1974;33:916-22.

3 Fentiman IS. Effective treatment of malignant pleural effusions. Br J Hosp Med 1987;37:421-8.

4 Martini N, Bains MS, Beattie EJ. Indications for pleurectomy in malignant effusion. Cancer 1975;35:734-8.

5 Pollock AV. The treatment of resistant malignant ascites by insertion of a peritoneo-atrial Holter valve. $\mathrm{Br} J$ Sur 1975;62:104-7.

6 Weese JL, Schouten JT. Pleural peritoneal shunts for the treatment of malignant pleural effusions. Surg Gynaecol Obstetr 1982;154:391-2.

7 Milsom JW, Kron IL, Rheuban KS, Rodgers BM. Chylothorax: an assessment of current surgical management. $J$ Thorac Cardiovasc Surg 1985;89:221-7.

8 Daly WJ, Bondurant S. Direct measurement of respiratory pleural pressure changes in normal man. $J$ Appl Physiol 1963;18:513-8.

9 Tarin D, Price JE, Kettlewell MGW, Souter RG, Vas ACR, Crossley B. Clinicopathological observations on metastasis in man studied in patients treated with perimetastasis in man studied in patients treated with 